\title{
Inflorescence morphology and development of suweg (Amorphophallus paeoniifolius (Dennst.) Nicolson
}

\author{
TRI HANDAYANI", YUZAMMI, JULISASI TRI HADIAH \\ Research Center for Plant Conservation and Botanic Gardens, Indonesian Institute of Sciences. Jl. Ir. H. Juanda 13, Bogor 16122, West Java, Indonesia. \\ Tel./fax.: +62-251-8322187, `email: irtri@yahoo.co.id
}

Manuscript received: 7 November 2020. Revision accepted: 27 November 2020.

\begin{abstract}
Hanfayani T, Yuzammi, Hadiah JT. 2020. Inflorescence morphology and development of suweg (Amorphophallus paeoniifolius (Dennst.) Nicolson. Biodiversitas 21: 5835-5844. Inflorescence of Amorphophallus paeoniifolius (Dennst.) Nicolson consists of two main parts: spathe and spadix. Detailed information on its development, however, is not yet available. This study aimed to investigate the development and morphology of suweg's inflorescence, to reveal the anthesis of male and female flowers, and to observe its insect visitors. The study observed 46 inflorescences, ten of which were measured for detailed developments. Inflorescences were observed from bud emergence to withering during one flowering cycle. The results showed that the flowering process included six phases which altogether required 22 to 36 days, namely the developments of inflorescence bud, cataphyll, spathe and spadix, appendix, fully bloomed inflorescence, and flowers anthesis. The inflorescence height including peduncle was $48-75 \mathrm{~cm}$, spathe $19-50 \mathrm{~cm}$ long, spathe circle 65-176 cm, appendix 13-33 cm long, and appendix circle 45-80 cm. Three appendix forms were observed: ovate $(43.48 \%)$, triangular conic (41.30\%), and rounded (15.22\%). Female flower anthesis occurred one day prior to male flower anthesis. Insect visitors found during anthesis were Lucilia sericata (Calliphoridae), Sarcophaga sp. (Sarcophagidae), and Trigona speciosa (Apidae).
\end{abstract}

Keywords: Amorphophallus paeoniifolius, appendix, insect visitors, spadix

\section{INTRODUCTION}

The genus of Amorphophallus belongs to the Araceae family, consists of over 200 species (Mayo et al. 1997; Jaleel et al. 2011, 2012), 63 species of which are distributed in Malesian region (Boyce and Wong 2015; Yuzammi et al. 2017) and more than 26 species were found in Indonesia (Yuzammi et al. 2017). The genus is dispersed worldwide from Africa, Madagascar, India, Southeast Asia, Malesia through north-east Australia where Southeast Asia and West Malesia are considered to be the richest in species diversity (van der Ham et al. 1998; Yuzammi et al. 2017). Amorphophallus paeoniifolius (Dennst.) Nicolson or suweg is widespread in Indonesia and distributed in almost all Indonesian islands such as Sumatera, Kalimantan, Sulawesi (Sugiyama et al. 2010), Jawa (Hidayat 2019; Mutaqin et al. 2020), Bali and Lombok (Kurniawan et al. 2011), Flores and Timor (Jansen et al. 1996) and West Papua (Yuzammi et al. 2014).

The life cycle of Amorphophallus comprises two stages: vegetative and generative (Kumar et al. 2015) and usually fall into dormant in between. The vegetative stage usually occurs during wet season and dormant in dry season (Santoso et al. 2006). When the dormant stage is over, it still then followed by either a generative stage or another vegetative stage. The generative stage is indicated by the appearance of an inflorescence bud.

Amorphophallus inflorescence consists of two main parts: spathe and spadix (Korotkova and Barthlott 2009; Kumar et al. 2015; Yuzammi et al. 2017). This genus has protogyny type in which the pistils mature before the stamens (Seymour and Matthews 2006; Punekar and Kumaran 2010; Kumar et al. 2015), thereby selffertilization never occurred. Although self-pollination does not occur, the inflorescence produces seeds with the help of insect pollinators such as beetles, bees, and flies (Gibernau 2003, 2011; Jimènez et al. 2019), ants, and cockroaches (Punekar and Kumaran 2010).

During female anthesis, the spathe is fully open, and subsequently, thermogenesis occurs in which the spadix is heat up and release a kind of steam through an appendix. This process synthesizes aromatic compounds to attract pollinators (Garcia et al. 2008). Moreover, Seymour and Matthews (2006) as well as Punekar and Kumaran (2010) mentioned that suweg inflorescence produced a specific aromatic as sickening gas or rotting flesh in order to attract insect visitors.

Amorphophallus paeoniifolius (suweg) is one of species with edible tuber and has been cultivated in various countries, for instance in India, the Philippines, Malaysia, Vietnam (Singh and Wadhwa 2014; Kumar et al. 2015; Truyen et al. 2015; Singh et al. 2016) and in Indonesia (Santosa et al. 2017; Putri et al. 2018; Mutaqin et al. 2020). The suweg's tuber contains a lot of energy, glucose, starch, protein, and mineral (Sugiyama and Santosa 2008; Yuzammi 2009; Singh and Wadhwa 2014). Moreover, it is also used for gastro protective, analgesic, anti-helminthic, anti-diarrheal, anti-bacterial, antioxidant, anti-tumor, immunomodulatory, and rheumatic (Khan et al. 2007; Gopi et al. 2008; Singh and Wadhwa 2014). 
Suweg has been the subject of many studies including taxonomy (Mayo et al. 1997; Jaleel et al. 2011, 2012), propagation (Soemono et al. 1986; Kumar et al. 2015), pollen and pollination (van der Hamet et al. 1998; Punekar and Kumaran 2010; Gibernau 2011; Jimènez et al. 2019), flower induction (Santosa et al. 2006), ethnobotany (Arva et al. 2013; Singh and Wadhwa 2014; Kumar et al. 2015; Singh et al. 2016, Mutaqin et al. 2020), leaf anatomy (Gopi et al. 2008), distribution (Sugiyama et al. 2010; Kurniawan et al. 2011; Yuzammi et al. 2014; Hidayat 2019) and thermogenesis (Lamprecht and Seymour 2010). However, research on suweg's inflorescence is yet very limited. In addition, information on flowering is crucial for crossfertilization purposes to produce seeds and prime variety of suweg. This study provided knowledge on morphology of suweg's inflorescence development and insect visitors.

\section{MATERIALS AND METHODS}

\section{Plant material and research location}

This study used suweg collections at Bogor Botanic Gardens (BBG), which were originated from Lampung, Yogyakarta, and Madiun, Indonesia. The research was conducted at the nursery of BBG, from August to December 2019. The garden is located at $260 \mathrm{~m}$ elevations, with air humidity $34-80 \%$ and air temperature $25-39^{\circ} \mathrm{C}$ during research observation. Quantitative data were recorded from 10 inflorescences out of 46 observed plants. The growth and development of inflorescence were observed every day during the study at the BBG.

\section{Floral morphology observation}

Observations on suweg's floral morphology of ten selected inflorescences included cataphyll, peduncle, spathe, female and male flowers, as well as appendix. All of these inflorescence parts were measured (Figure 1), such as lengths of cataphyll and peduncle, length and circle of spathe, male and female zones, and appendix. RHS color chart was used for color determination, for instance, orange-white (159B), yellow-green (145C, 145D). The numbers followed by letters in brackets indicated the color use of the RHS color chart.

\section{Inflorescence development observation}

Forty-six inflorescences were observed for their inflorescence development, particularly of the growth of cataphyll, spathe, spadix, female and male flowers anthesis, as well as the development of flowers after fully bloomed. The observation on inflorescence development started from $3-5 \mathrm{~cm}$ inflorescence bud to the flower fully bloom, withering, and comes off. These observations were conducted every day. Each inflorescences development was recorded using Canon Power Shot SX160IS camera. Female anthesis was recognized when the spathe was fully opened and released nasty smell, and the pistil became sticky. Male anthesis was indicated by theca opening then released golden-yellowish pollen. The occurrence of thermogenesis was indicated by several things. Appearance of droplets on spadix surface indicated an increase in spadix temperature. Higher temperatures would produce more droplets. Emission of stench also indicated thermogenesis is occurring. In addition, presence of insect visitors can also be used as an indicator of thermogenesis. Other data regarding thermogenesis was supported by literature. Identification of insect visitors was observed during anthesis.
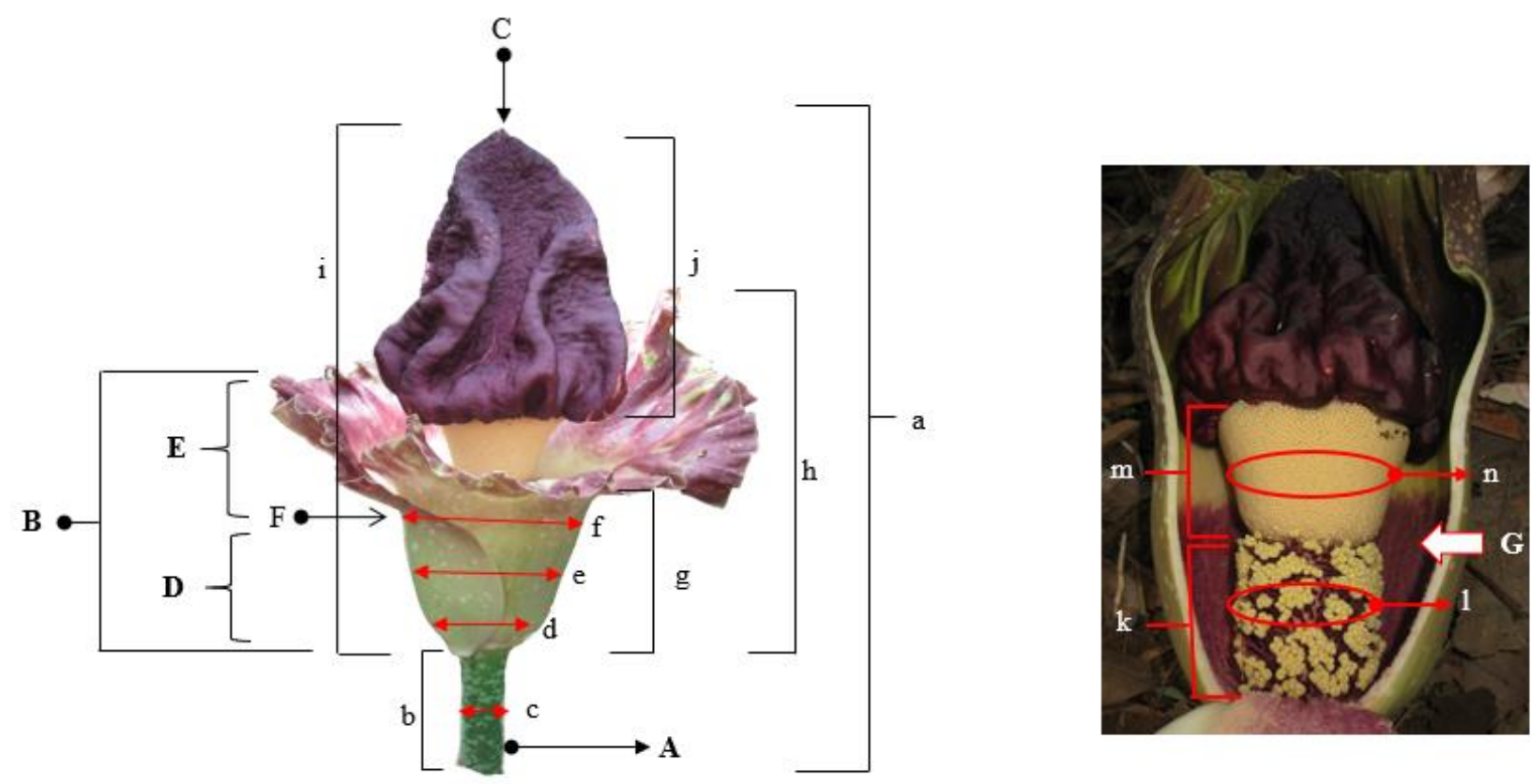

Figure 1. Suweg inflorescence parts: A. Peduncle, B. Spathe, C. Spadix, D. Spathe Tube, E. Spathe Limb, F. Constriction, G. Floral Chamber. Suweg measurements: a. Inflorescence length, b. Peduncle length, c. Diameter of peduncle, d. Diameter of lower spathe tube, e. Diameter of middle spathe tube, f. Diameter of upper spathe tube, g. Length of front spathe, h. Length of back spathe, i. Spadix length, j. Appendix length, $k$. Length of female zone, l. Circumference of female zone, m. Length of male zone, n. Circumference of male zone 


\section{RESULTS AND DISCUSSION}

\section{Inflorescence morphology}

When a new bud emerged from a suweg tuber following a dormant stage, it could be either a leaf bud or an inflorescence bud (Figure 2.A). A leaf bud can be differentiated from an inflorescence bud by its shape and hardness. The bud hardness was checked by gently pressed using pointer finger and thumb. A leaf bud is narrowly elliptical with a pointed tip and rather hard (Figure 2.B). Whereas, an inflorescence bud is broadly elliptical with a rounded tip and soft (Figure 2.C).
Suweg inflorescences can be divided into several parts, viz; cataphylls, peduncle, spathe, and spadix, with each part has different purpose, shape, size and color. The ten observed inflorescences showed similarities in flower structure, and differences in color and shape. Suweg's inflorescence formed a bell-shape or campanulate. The spadix beared separated zones of female, male, and sterile male flowers (appendix) (Figure 3). Male and female flowers were sexual reproductive organs which would produce fruits when pollinated. Whereas, the appendix has function to release nasty smell through its pores during female anthesis.
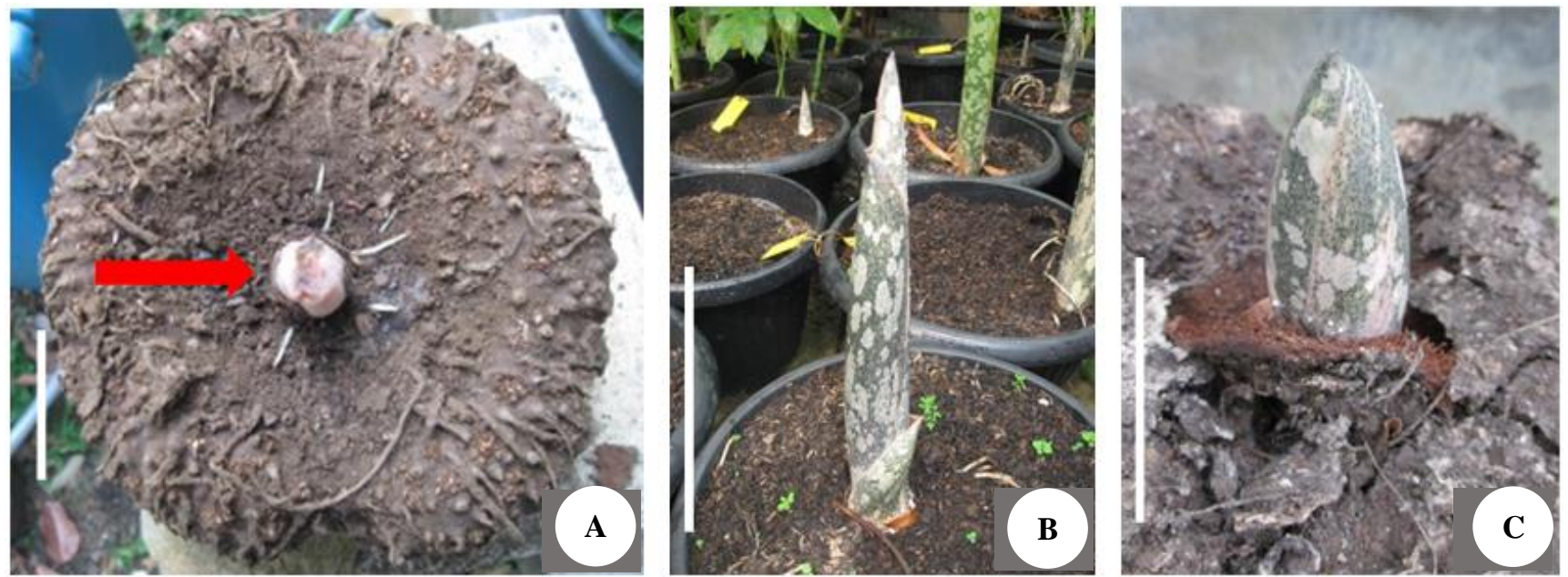

Figure 2. A. Tuber with the main bud at the center (red arrow), B. Leaf bud, C. Inflorescence bud. Scale bar $=5 \mathrm{~cm}$
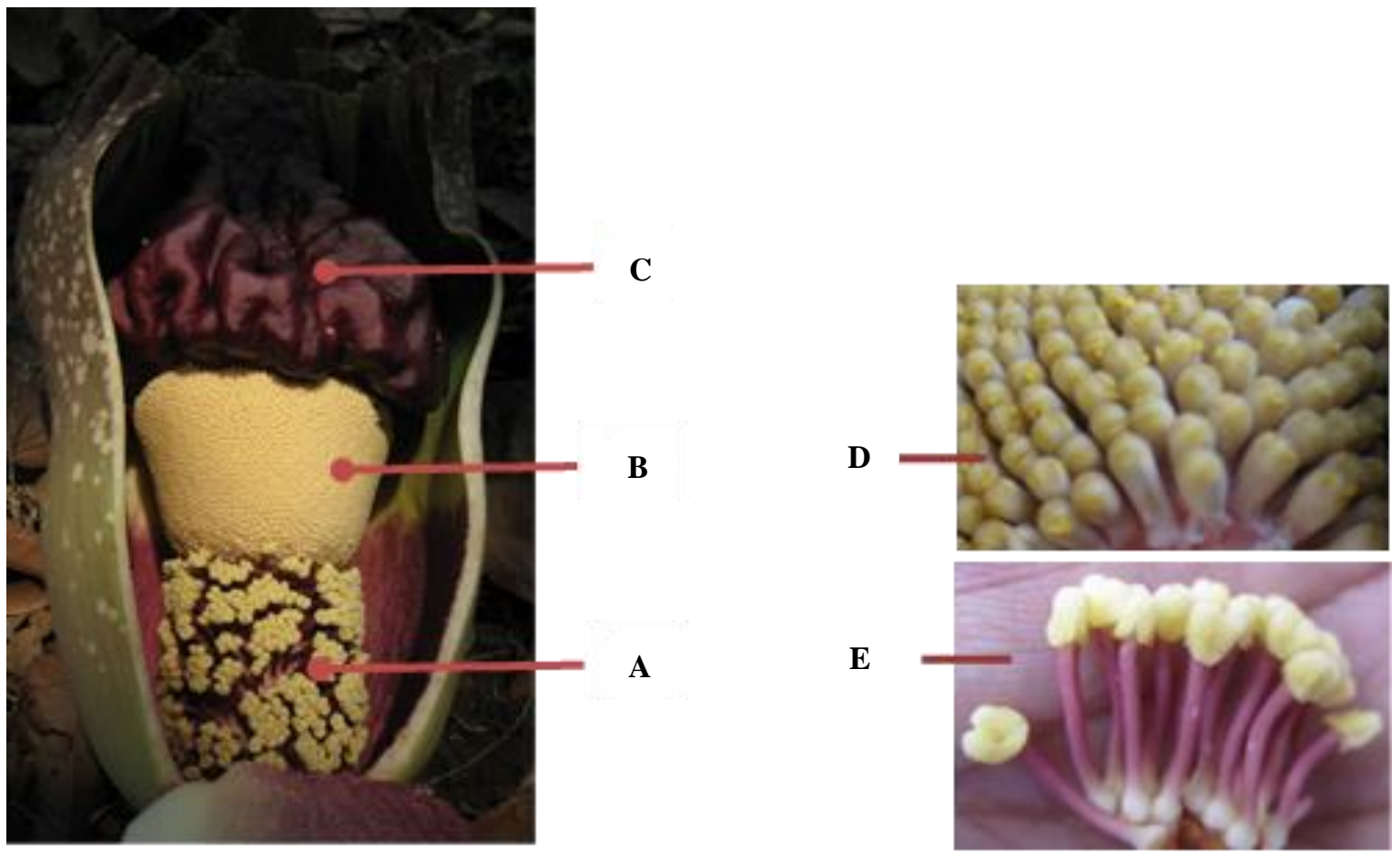

Figure 3. A suweg inflorescence with the spathe cut open showing the spadix with its parts inside: A. Female zone, B. Male zone, C. A maroon appendix at the tip, D. Male flowers, E. Female flowers 


\section{Peduncle}

Suweg inflorescence was supported by a short peduncle which was attached to the tuber, cylindrical in shape, somewhat smooth to rough surface, 6-21 cm long and 2.6$6.1 \mathrm{~cm}$ in diameter. The color of peduncle was green (138A, 139B, 141D, 143A), usually with mixtures of large and small blotches and various shades of green (130C, $134 \mathrm{C}, 138 \mathrm{~B})$, greyish white $(156 \mathrm{~A})$, greyish orange (164D, 174D, 170D), orange-white (159B), yellow-green (145C, 145D). It turned dark brown when it dried out, and subsequently, it would be detached from the tuber indicating the generative stage was over and a dormant stage would follow.

\section{Cataphyll}

Cataphyll is a modified leaf that lacks a blade and in appearance corresponds to a petiole sheath (Boyce et al. 2012). The purpose of cataphylls in suweg inflorescence was for enveloping and protecting the inflorescence bud until it was fully opened. The cataphyll was usually 3 to 4 , elliptic in shape with acute tip and entire margin. The first cataphyll was smallest and outermost in position. Subsequent cataphylls usually increased in size towards inward. The second cataphyll size was $3-9.5 \mathrm{~cm}$ long and 3-9 $\mathrm{cm}$ wide, and the third was $6-17 \mathrm{~cm}$ long and 5-10.5 $\mathrm{cm}$ wide. The color was yellow-green (147A) outside and white (N 155C) inside with white blotches (155A, NN 155A).

\section{Spathe}

Spathe is a simple, bract-like foliar organ associated with the spadix and usually colored (Yuzammi et al. 2017). It is usually attractive with various kinds of shapes. The spathe of suweg was bell-like or campanulate, broad. Its lower part (tube) was often separated from its upper part (limb) by a shallow constriction. Spathe tube was rounded with overlapping margin, clockwise or sometimes counterclockwise, while the limb was strongly undulate. Length of front spathe was 19-31 cm while length of back spathe was $27-50 \mathrm{~cm}$. Diameter of spathe tube is divided into three parts: lower, middle, and upper parts. Each of the diameters is $8.6-16.2 \mathrm{~cm}, 10.5-21 \mathrm{~cm}, 20.7-56.1 \mathrm{~cm}$, respectively. The color of the spathe was bright to attract insect visitors. The tube colour (outside) varied from yellow-green (144C\&D, 145C, 146D, 147C\&D, 166A), greyish-green (194B, 195B, 197A), and greyish-orange (166A), usually with large and small circular paler spots ranging from green-white (157A\&B), white NN (155B), greyish-white (156A), yellow-green (145C\&D) and orange-white (159B). The limb was also variable in colour; yellow-green (145A, 146B), greyish-brown (N199A, 199D), greyish-green (197A), greyish-purple (187 A), greyish-orange (174 D, 176A, 165A, 166A), purple (49C) and brown (200C), usually suffused with large and small blotches of yellow-green (144C, 145A\&B, 146B, 148A\&D), green (N137A), grey (201A), yellow-white (155A), orange-white (159A), brown (200C) and greyishorange (N170D, 174D).

\section{Spadix}

Spadix was composed of three main parts; female zone (Figure 3.A), male zone (Figure 3B), and appendix (Figure 3.C) and enveloped inside the spathe. The female zone was cylindrical, 10-19.5 cm length, 4.8-7.3 cm in diameters, where many pistils were attached. A pistil consisted of an ovary, a style, and a stigma. The male zone was cup-like, broader at the top, 7-12 cm length, 5.7-10.2 cm in diameters, consisted of a bunch of male flowers, yelloworange (17 D, 18B) or yellow group (11D) in color. The appendix was bright in color and emitted nasty smell through its pores, which both functioned to attract insect visitors. The shape of appendix varied from conoid, pyramidal to globose. The outer surface was grooved, undulate, and glossy, either before or during anthesis. The appendix was $13-33 \mathrm{~cm}$ in length and $13.4-25.5 \mathrm{~cm}$ in diameter, greyish-purple (187A, N187A, N186B), greyishorange (166A), brown (200A), and Grey-brown (N 199D) in color.

\section{Inflorescence development}

A generative stage was indicated by an emergence of inflorescence buds to fully bloomed, through a series of growths and developments. Observation was started when the inflorescence bud was $5 \mathrm{~cm}$ high until it was fully bloomed. The inflorescence development covered six stages, namely the developments of bud, cataphyll, spathe, appendix, full blooming, and anthesis (Figure 4). Each stage has different length time of growth. Following anthesis, the inflorescence withered gradually till the peduncle came off and the plant became dormant again.

\section{Stage 1. Bud development}

Inflorescence bud usually emerged in the middle of the tuber, elliptical in shape with rounded tip and tightly wrapped by cataphylls (Figure 4.A). This bud initially appeared after a 57-127 day dormancy. Its size corresponded to the tuber size, the larger tuber size resulted in bigger bud size. Inflorescence bud grew both in height and width, whereas leaf bud only increased in height.

\section{Stage 2. Cataphyll development}

Growth and development of inflorescence bud reflected all components of inflorescence (cataphyll, peduncle, spathe, and spadix) (Figure 4.B-D). Stage two was indicated by the growth and development of 2-4 cataphylls whereby one has dried when reached $7-8 \mathrm{~cm}$ high, occurring 3-7 days after stage 1 over. The rest remained until the inflorescence fully open. The outermost cataphyll (second cataphyll) wrapped the inflorescence bud tightly including the other cataphylls. Subsequently, the third and fourth cataphylls grew rapidly and exceeded the second cataphyll. The bud continuously grew and the second cataphyll edge gradually loosens then its tip released from the bud. This process occurred between 6 to 11 days (Figure 4.B) and when the average bud height was 20.50 $\mathrm{cm}$.

After the second cataphyll was released, the third cataphyll replaced to wrap the bud tightly. The fourth 
cataphyll grew, along with the bud inflorescence, and exceeded the third cataphyll height. Both edges of the third cataphyll then became loose and released its tip, and the fourth cataphyll was visible (Figure 4.C). It occurred in 10 to 12 days after stage 1 over and average bud was $25.33 \mathrm{~cm}$ high. While the third cataphyll was pulled backward, the edges of the fourth cataphyll stretched and slightly showed a conspicuous spathe (Figure 4.D). The average height of the bud at this stage was $34.13 \mathrm{~cm}$. The whole process in this stage took 3-14 days.

\section{Stage 3. Spathe development}

This stage was indicated by the first appearance of spathe and the release of the fourth cataphyll (Figure 4.E$\mathrm{H})$. Beginning with an edge of the third cataphyll detached meanwhile the other still attached to fourth cataphyll, the growth and development of spathe began. The spathe enlarged and required more spaces; therefore, it had pushed both cataphylls (Figure 4.E). In this stage, the average height of inflorescence was $35.16 \mathrm{~cm}$. Previously, the two edges of the fourth cataphyll tightly enveloped the spathe before pressed by the spathe, thereby opening both. The bigger spathe size, the widest cataphyll fourth opened (Figure 4.F). The inflorescence continuously grew until reached and penetrated the tip of the cataphyll fourth though small part of the spathe was still enveloped by the cataphyll (Figure 4.G). At this stage, the average height of inflorescence was $48 \mathrm{~cm}$. By increasing of inflorescence size, the fourth cataphyll was no longer be able to wrap the spathe and gradually fell off; thereafter, the entire spathe unwrapped (Figure 4.H). The entire process occupied 10 19 days; and the inflorescence height was $52.33 \mathrm{~cm}$.

The spathe varied in color due to the presence of chlorophyll, carotene, and anthocyanin pigments. A green color, notably in spathe tube, presumably played a role in photosynthesis. Croft and Chen (2017) stated that chlorophyll was in charge of green color and a primary pigment for photosynthesis; as found in leaf during vegetative stage. Further research is required whether the green color on spathe and peduncle at generative stage carried out photosynthesis and substituted a leaf function. A bright color was found at a limb, caused by the presence of carotene and anthocyanin compounds. The carotene pigment is, actually, closely related to yellow formation in plant, while the anthocyanin is closely related to appearance of red, purple, and black (Schaefer and Rolshausen 2005). However, bright color in spathe has a function to attract insect visitors. The spathe was clearly visible and shiny before and during female anthesis (Figure 4.J-K), and turned dull (Figure 4.L) when it was over. Besides, a bright spathe color could be used as a marker and to lead insect visitors to find the appendix easier, particularly for a plant with small cone-like appendix. Further research is required for proving it.

\section{Stage 4. The developments of appendix}

Stage four was indicated by increasing length of the appendix following the opening of the spathe's tip (Figure 4.I) and an average height of inflorescence was $55.25 \mathrm{~cm}$. The appendix continuously grew, enlarging, and elongated (Figure 4.J) then terminated when the inflorescence was fully bloomed (Figure 4.K). At this time the inflorescence height was ca. $65 \mathrm{~cm}$. This appendix development process took 15-24 days since the bud appeared.

Bright colors and distinctive odor were found in appendix for attracting insect visitors. This bright color was influenced by anthocyanin pigment and was variable among the appendixes though some could be similar (Table 1). The insect visitors would identify appendix easier when it became shinier prior to and during female anthesis. The brightness was lacking when the anthesis was over. The changes in color brightness were related to the need for pollinators.

This study found three kinds of appendix forms; conical, pyramidal and rounded (Figure 5). The 46 observed inflorescences showed conical (43.48\%), pyramidal (41.30\%), and rounded (15.22\%) forms, whereas Punekar and Kumaran (2010) showed that appendixes shapes found in suweg were globose, conoid and amorphous. However, variation of suweg's appendix shape did not show any differences in species level. Even though the appendix characters could be used in delimiting species within the genus, but they cannot be used alone and should be used together with other characters of the inflorescence as a whole.

The development of appendix with conical form took 6-11 days, 7-14 days for pyramidal form, and 12-14 days for rounded form. The conical form was the smallest and fastest development of appendix compared to other shapes.

\section{Stage 5. Fully bloomed inflorescence}

This stage was presented by fully opened limb (Figure 4.K). The result showed that fully opened limb occurred in the morning (08.00-10.00 am) or in the afternoon (02.00$0500 \mathrm{pm})$. At this stage, maximum spathe circumference and diameter were reached whereby the limb circumference was $176 \mathrm{~cm}$ and diameter was $56.1 \mathrm{~cm}$; circumference of spathe constriction was $66 \mathrm{~cm}$ and $21 \mathrm{~cm}$ in diameter, and spathe tube circumference (middle) was $51 \mathrm{~cm}$ and $16.2 \mathrm{~cm}$ in diameter. The limb opened wider, fringed edge, bright and shiny in color. The tube till constriction part overlapped forming floral chamber (Figure 1.G).

Several important activities during full blooming included female and male anthesis, thermogenesis, and attracting of insect visitors. All of the process, from emerging inflorescence bud to fully bloomed took 22-36 days. 

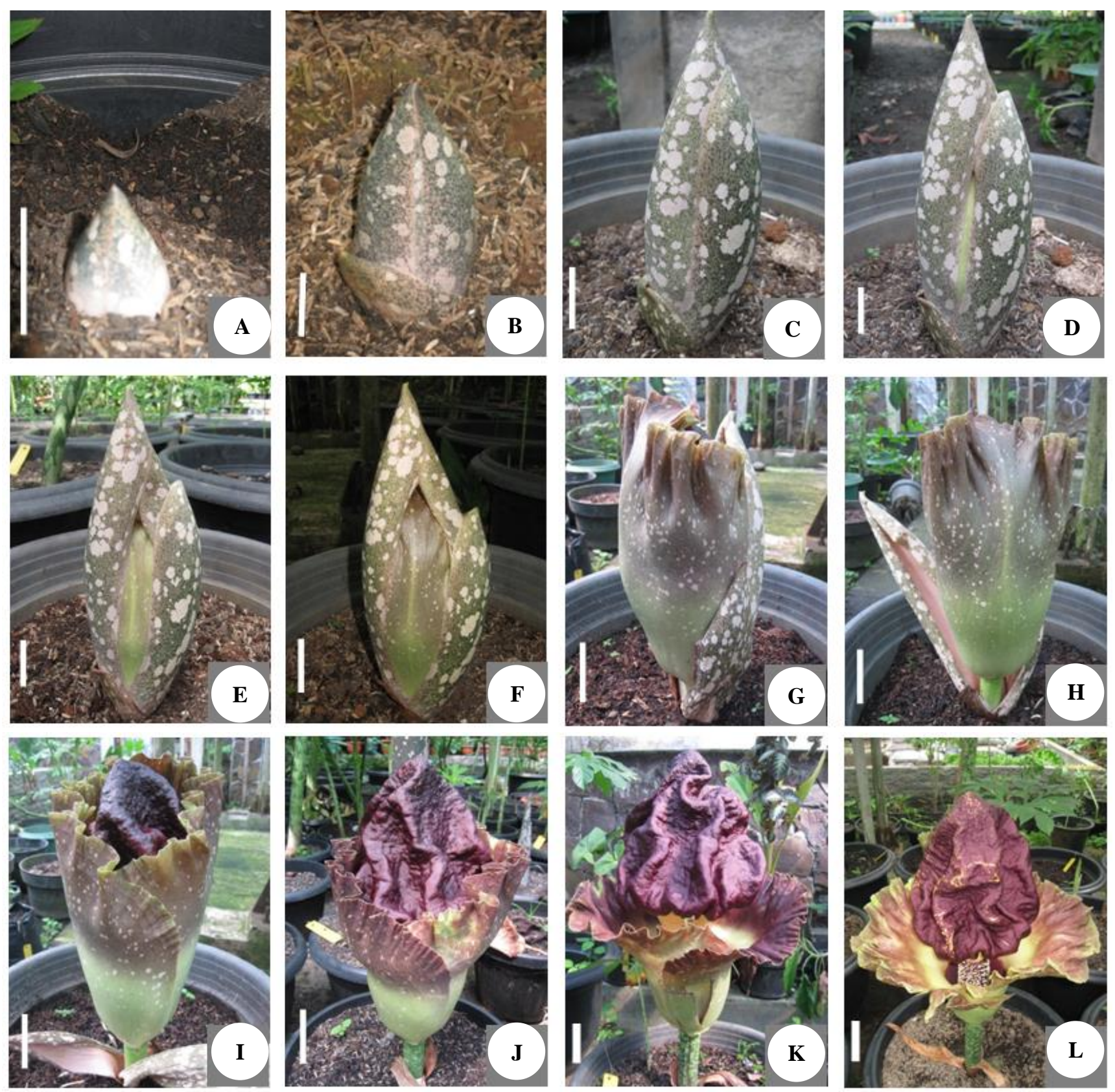

Figure 4. The growth of suweg inflorescence. A-B. bud development, C-D. cataphyll development, E-H. spathe development, I-J. appendix development, $\mathrm{K}$. fully blooming inflorescence, $\mathrm{L}$. beginning of withering. Scale bar: $\mathrm{A}-\mathrm{F}=5 \mathrm{~cm} ; \mathrm{G}-\mathrm{L}=10 \mathrm{~cm}$

Table 1. The appendixes color variation (the appendix was divided into three parts: lower, middle, and upper)

\begin{tabular}{cll}
\hline & Appendixes color & \\
\hline Below & \multicolumn{1}{c}{ Middle } & Upper \\
\hline Greyed-orange 164 B & Greyed-orange 164 A & Greyed-orange 176 B \\
Greyed-orange 176 B & Greyed-purple N 186 C & Greyed-purple 187 A \\
Greyed-yellow 161 A & Greyed-orange 166 A & Greyed-purple 187 A \\
Greyed-purple N 187 A & Greyed-purple N 187 A & Greyed-purple N 187 A \\
Grey-brown N 199 A & Greyed-orange 200 A & Brown 200 A \\
Greyed-purple N 186 C & Brown 200 B & Brown 200 B \\
\hline
\end{tabular}



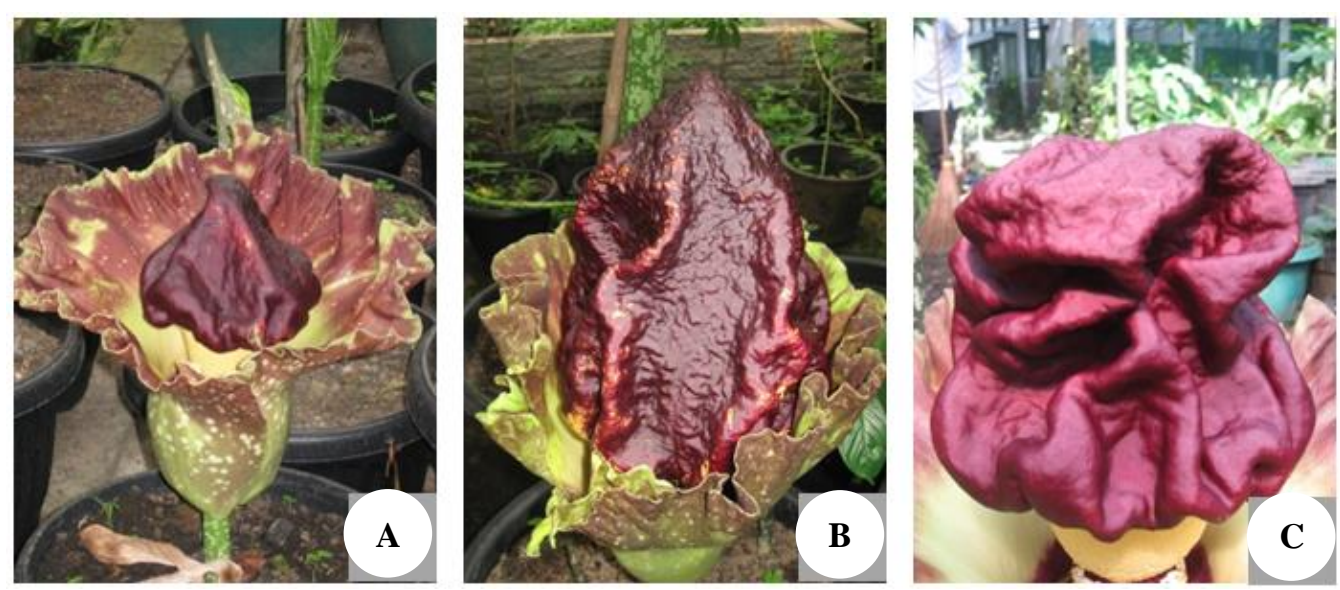

Figure 5. The appendix shapes. A. Conical, B. Pyramidal, C. Rounded

\section{Stage 6. Anthesis}

Anthesis is the time of full opening of a flower when pollen is first dispersed, and/or stigma is receptive (Yuzammi et al. 2017). Suweg inflorescence is classified as protogyny type in which female flowers anthesis first before male flowers anthesis. Female flower anthesis occurred when the inflorescence was fully bloomed, or sometimes not fully opened yet. However, it was noticeable due to an unpleasant odor resemble smell of a rat carcass or rotten fish, emanated from the appendix pores. Carcasssmelling was produced by dimethyl disulfide and dimethyl trisulfide (Lamprecht et al. 2002), dimethyl oligo-sulfides (Kite and Hetterscheid 1997, Punekar and Kumaran 2010). Similarly, A. titanum also produced carcass-smelling emanated during female anthesis, due to contributed of some chemical compounds; dimethyl oligo-sulfides, dimethyl trisulfide (Kate and Hetterscheid 1997), trimethylamine (Fujioka et al. 2012), methyl thiol acetate, 3-methyl butanal, acetic acid, isovaleric acid, 3-Hydroxy-2butanone, 2-Ethyl hexanol, and benzyl alcohol (Shirasu et al. 2010; Raman et al. 2017). This carcass-smelling attracted olfactory pollinators and insect visitors for coming, such as blowflies (Calliphoridae), and also as a sign for female anthesis.

One day after the spathe was fully opened, the carcasssmelling emanated even more, especially early in the morning (before sunrise) to attract insect visitors. During daytime, the carcass-smelling reduced slightly, probably caused by the sunlight. When the anthesis occurred in the afternoon, the carcass-smelling emanated from noon until night to attract nocturnal beetles.

Male flowers anthesis started when the female flowers anthesis was over, indicated by dispersion of pollen (yellow in color). During male flowers anthesis, unpleasant odor vanished, and no more insect visitors were found. Moreover, the color of spathe and appendix also changed, both turned dull.

\section{Thermogenesis}

Thermogenesis in Araceae is the process of heat emission which occurs in the spadix, and plays important role in pollination. It usually occurs in insect-pollinated and protogynous plants, in which female flowers ripen before male flowers (Seymour and Matthews 2006). Floral heat production is generally associated with odor emissions, arrival of pollinators, and release of pollen (Chouteau et al 2007). Prakash and Nayar (2000) reported that thermogenesis (in Araceae) occurs in two phases during anthesis of the female flowers and then at anthesis of male flowers.

The spadix emits heat during the first phase (female anthesis). The ten observed inflorescences showed that thermogenesis started when spathe blooms, which took place both in the morning or afternoon. When anthesis occurred in the female flowers, temperature of the spadix increased and heat and foul odor were emitted through the pores on appendix surface. The heat production was different for each inflorescence. This was shown by the different amounts of water droplets that appeared on the surface of the appendix (Figure 6). The higher the temperature, the more droplets on the surface. When anthesis occurred in the morning, thermogenesis reached its peak in the morning, then decreasing during the day, and was over in the afternoon. When anthesis occurred in the afternoon, thermogenesis reached its peak in the afternoon, then decreasing and over by night time.

Lamprecht et al. (2002) measured thermogenesis temperature of two flowering A. paeoniifolius at Berlin Botanic Garden. Anthesis occurred in the morning with a room temperature of $17.2^{\circ} \mathrm{C}$ and $70 \%$ humidity. During anthesis that occurred at $9 \mathrm{am}$, temperature of the spadix was $26.3-26.8^{\circ} \mathrm{C}$. It was then decreasing during the day and disappeared at $4 \mathrm{pm}$. The highest temperature was found inside the floral chamber.

The second phase (male anthesis) occurred 24-26 hours after the first phase ended (Prakash and Nayar 2000). The appendix no longer emitted odor nor heat. 

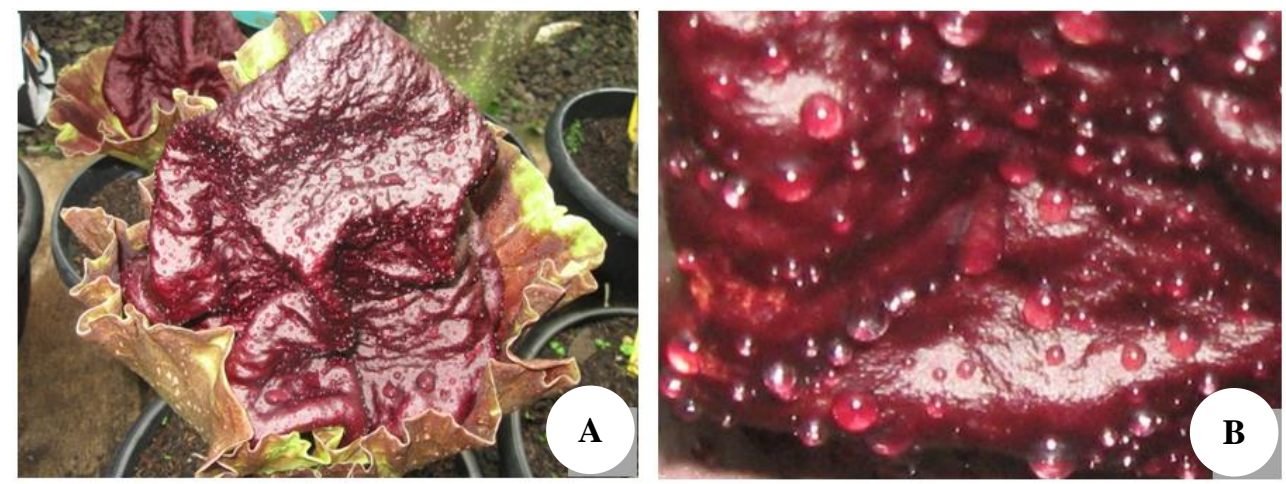

Figure 6. Water droplets appeared on the appendixsurface of A. paeoniifolius, A. Showing thermogenesis happening in the inflorescence; B. Close up of the droplets

\section{Insect visitors}

Amorphophallus needs other agents such as insects to assist with pollination due to the different anthesis times of the male and female flowers. Therefore, Amorphophallus inflorescence offers rewards to attract pollinators, such as visual and olfactory signals (Lamprecht et al 2002). The visual signals include the shape and color of spathe and appendix, and peduncle length. The olfactory signals include the stench odor emitted by the appendix during female anthesis.

Amorphophallus forms a floral chamber (Figure 1.G) that functions as a reward as well as a trap for the insect visitors. Jim'enez et al. (2019) stated that floral chambers provide a safe place as rewards for insect pollinators. Insect visitors stay in the chamber for up to 48 hours, where they feed on pollen, liquid on stigma, or other floral tissues, as well as keeping themselves warm and mating. Visiting insects include pollinators and non-pollinators. The former performs a mutualism relationship with the visited inflorescence, while the latter does not provide any benefits to the visited inflorescence. Insect pollinators and the visited inflorescence become parts of each other's reproduction cycles. Insect pollinators assist the inflorescence pollination, and in return, the visited inflorescence provide food and a safe place to reproduce (Punekar dan Kumaran 2010).

Gibernau (2003) reported some insect visitors to the inflorescence of Amorphophallus, including beetles (Asilidae, Nitidulidae, Scarabidae, Hybosoridae), bees (Trigona), and flies (Calliphoridae, Platystomatidae). However, not all visiting insects are pollinators.

Punekar and Kumaran (2010) observed inflorescence of A. paeoniifolius in India, and found that the appendix emits stench odor whole day, with the most stench during 18.0021.00. They found some insect visitors to the inflorescence, including Onthophagus, Heliocopris (Scarabaeidae); black beetles (Cetoniidae), Musca domestica (Muscidae), blowflies (Calliphoridae). Among these insects, the beetles (Cetoniidae family) are the only real pollinators for this plant.

This study found that insect visitors to A. paeoniifolius inflorescence at Bogor Botanic Gardens were blowflies (Calliphora vomitoria, Calliphoridae), fleshflies (Sarcophaga sp., Sarcophagidae), houseflies (Musca domestica, Muscidae), stingless bees (Trigona sp., Apidae), hoverflies (Syrphidae) and sap-feeding beetles (EpuraeaHaptoncurina, Nitidulidae) (Figure 7). Among these insects, Trigona sp. (Apidae) seemed to be the only pollinator since it is the only visiting insects that were active in the reproduction zones of the inflorescence with their legs and wings full of pollens (Figure 7.A).

During female anthesis, appendix of A. paeoniifolius produced sulfides as olfactory signals for flies that love smell of carcasses. Blowflies responded to the smell and visited the spathe and appendix of the inflorescence. They were seen visiting the inflorescence whole day, and fed on the liquid from the pores on the spathe and appendix. However, they did not seem to be pollinator agents for this plant since they were not seen to visit the reproduction zones of the inflorescence. They were no longer seen around the plant after the female anthesis was over and the appendix no longer emitted carcass smell. This study was in line with that of Punekar and Kumaran (2020) who also found that blowflies are not pollinator agents for $A$. paeoniifolius. The flies only feed on the rotting proteins on the appendix and lay their eggs in the floral chamber. In addition, fleshflies and houseflies were also seen visiting the appendix and feeding on the liquid during 09.00-11.30 observation.

Insects found visiting into floral chamber during observation were stingless bees (Trigona sp.), hoverflies, and sap-feeding beetles. Trigona sp. visited the inflorescence in the morning $08.00-10.30$ and in the afternoon 14.30-16.00. The stingless bee did not visit the appendix, nor feed on the liquid. It fed on the pollen during male anthesis. It also picked up pollen on its legs and wings while flying from one flower to another.

Visiting hoverflies were also seen feeding on the pollen during male anthesis. However, there were no reports from previous works on the flies as an insect visitor or pollinator of A. paeoniifolius. This study found the flies visiting floral chamber, but not spathe nor appendix.

Punekar and Kumaran (2010) reported the presence of Haptoncurina beetles in floral chamber of A. paeoniifolius. They observed that the beetles feed on stigma liquid and take shelter in the chamber, but they are not pollinators for the plant. 

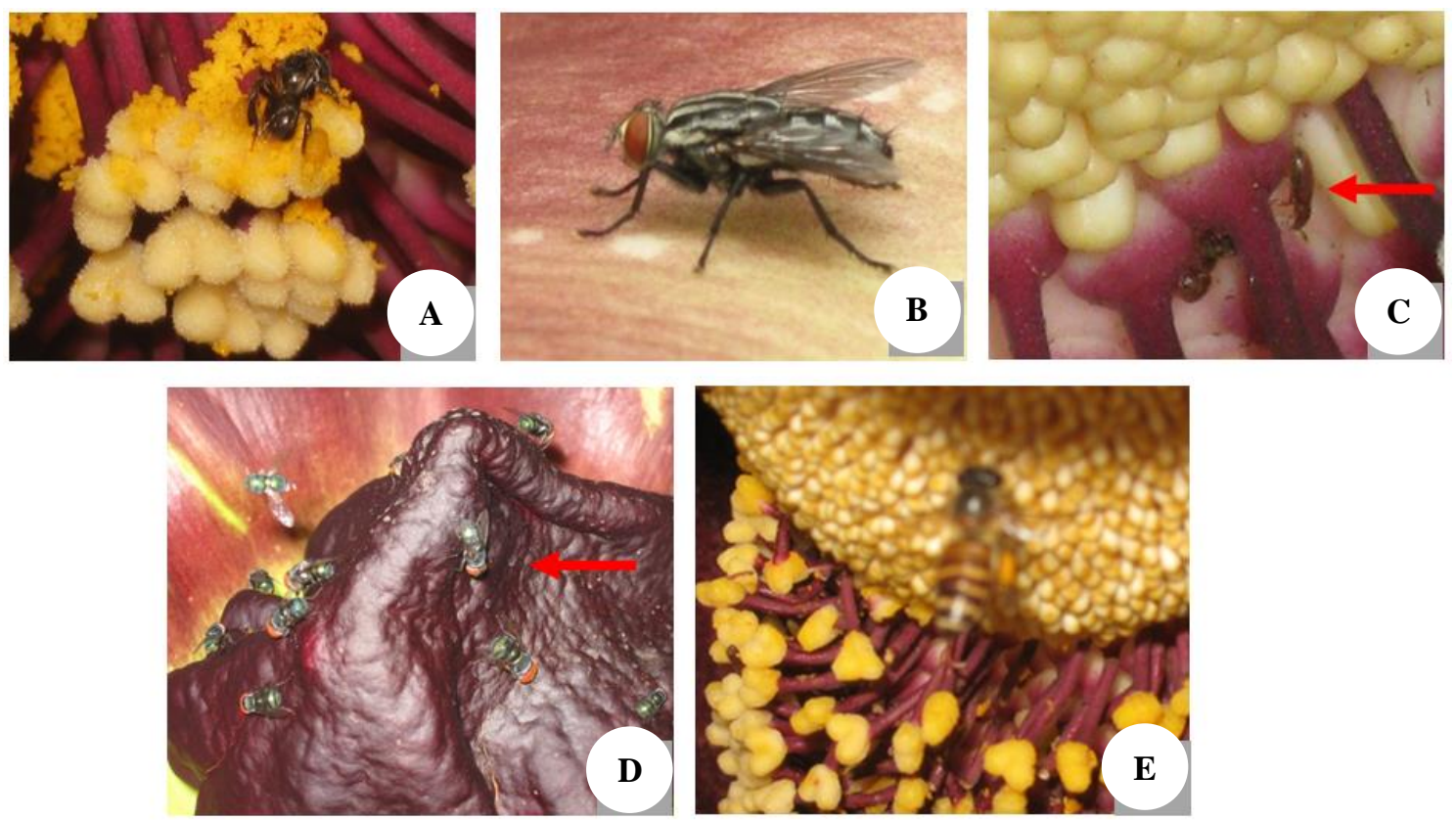

Figure 7. Insect visitors to A. paeoniifolius: A. Stingless bee (Trigona sp.), B. Flesh fly, C. Haptoncurina beetle, D. Blowflies, E. Hoverfly

\section{Over-bloomed inflorescence}

One day after A. paeoniifolius inflorescence was fully bloomed, the shine of spathe and appendix began to fade (Figure 4L), and no more rewards offered. Subsequently, no more insects visited either for pollination or other purposes. If pollination occurred during anthesis, the plant would produce fruits. Unfortunately, none of the ten observed inflorescences in this study produced fruits. This fertilization failure was probably due to different anthesis times of female and male flowers, so that cross-pollination has never occurred. As a result, the inflorescence withered in 3-5 days after fully bloomed, gradually rotten, and collapsed in 8-11 days. At last, the peduncle came off the tuber in 13 days after the spathe fully bloomed. Then, the plant started a dormant stage.

In conclusion, the result of this research showed that suweg's inflorescence formed campanulate or bell-shaped consisting of spathe and spadix. Three types of appendixes were found; cone, pyramidal and rounded. The development of suweg's inflorescence included six stages, starting from the emergence of inflorescence bud to fully blooming which took 22-36 days. The blooming of the spathe occurred in the morning or in the evening. It took 11-13 days after fully bloomed for the inflorescence collapsed and peduncle to detached from the tuber. Insect visitors found during anthesis were stingless bees (Trigona sp.), flesh flies, Haptoncurina beetles, blow-flies, and hoverflies. The latter is probably new record of insect visitors for A. paeoniifolius. The stingless bee Trigona sp. was presumably the only pollinator for this plant.

\section{ACKNOWLEDGEMENTS}

We would like to thank Sudarsono, Rosyidin, and Ahati of the Bogor Botanic Gardens nursery, who provided essential assistant and also looking after the plants during this research

\section{REFERENCES}

Arva HR, Bhaskar JJ, Salimath PV, Mallikarjuna AS. 2013. Anti-diabetic of elephant-foot yam (Amorphophallus paeoniifolius (Dennst.) Nicolson) in streptozotocin-induced diabetic. Intl $\mathrm{J}$ Biomed Pharmaceut Sci 7 (1): 1-6.

Boyce PC, Sookchaloem D, Hetterscheid WLA, Gusman G, Jacobsen N, Idei T, Van Du N. 2012. Flora of Thailand 11 (2): 1-221

Boyce PC, Wong SY. 2015. Compendium Genera Aracearum Malesianum. Aroideana 38: 40-177.

Chouteau M, Barabe D, Gibernau M. 2007. Thermogenesis in Syngonium (Araceae). Canadian J Bot 85: 184-190.

Croft H, Chen JM. 2017. Leaf pigment content. University of Toronto, Toronto, ON, Canada. DOI: 10.1016/B978-0-12-409548-9.10547-0A.

Fujioka K, Shirasu M, Manome Y, Ito N, Kakishima S, Minami T, Tominaga T, Shimozono F, Iwamoto T, Ikeda K. 2012. Objective display and discrimination of floral odors from Amorphophallus titanum, bloomed on different dates and at different locations, using an electronic nose. Sensors 12: 2152-2161.

Garcia JQ, Ivancic A, Lebot V. 2008. Morphological variation and reproductive characteristics of wild giant taro (Alocasia macrorrhizos), Araceae, populations in Vanuatu. N Z J Bot 45: 189203.

Gibernau M. 2003. Pollinators and visitors of aroid inflorescences. Aroideana 26: 66-83.

Gibernau M. 2011. Pollinators and visitors of aroid inflorescences: an addendum. Aroideana 34: 70-83.

Gopi R, Jaleel CA, Panneerselvam R. 2008. Leaf anatomical responses of Amorphophallus campanulatus to triazoles fungicides. Eur Asian J BioSci 2: 46-52.

Hidayat S. 2019. The study of suweg (Amorphophallus paeoniifolius) and other undergrowth species in teak plantation forest of Temengeng, Blora, Indonesia. Biodiversitas 20 (1): 37-42.

Jaleel VA, Sivadasan M, Alfarhan AH, Thomas J, Alatar AA. 2011. Revision of Amorphophallus Blume ex Decaisne. Sect. Rhaphiophallus (Schott) Engl. (Araceae) in India. Bangladesh J Plant Taxon. 18 (1): 1-26.

Jaleel VA, Sivadasan M, Alfarhan AH, Thomas J, Alatar AA. 2012. A taxonomic revision of Amorphophallus Blume ExDecaisne Sect. 
Conophallus (Schott) Engl. (Araceae) in India. Bangladesh J Plant Taxon. 19 (2): 135-153.

Jansen PCM, van der Wilk C, Hetterscheid WLA. 1996. Amorphophallus Blume ex Decaisne. In: Flach M, Rumawas F (eds) Plant Resources of South-East Asia No. 9. Plants Yielding Non-Seed Carbohydrate. Prosea, Bogor

Jimènez PD, Hentrich H, Aguilar-Rodr'ıguez PA, Krömer T, Chartier M, Mac Swiney GMC, Gibernau M. 2019. A review on the pollination of Aroids with bisexual flowers. Ann Missouri Bot Gard 104 (1): $83-$ 104.

KhanA, Rahman M, Islam S. 2007. Antibacterial, antifungal and cytotoxic activities of tuberous roots of Amorphophallus campanulatus. Turkish J Biol 31: 167-172.

Kite GC, Hetterscheid WLA. 1997. Inflorescence odours of Amorphophallus and Pseudodracontium (Araceae). Phytochemistry 46: 71-75.

Korotkova N, Barthlott W. 2009. On the thermogenesis of the Titan arum (Amorphophallus titanum). Plant Sign Behav 4 (11): 1096-1098.

Kumar RPK, Kolli SK, Suneetha J, Hemanth G. 2015. Cultivation on Amorphophallus paeoniifolius (Dennst.) Nicolson (elephant foot yam) in Kuvvur Mandal of West Godavari District, Andraphradesh India. Intl J Current Res 7 (05): 15549-15553.

Kurniawan A, Wibawa IPAH, Adjie B. 2011. Species diversity of Amorphophallus (Araceae) in Bali and Lombok with attention to genetic study in A. paeoniifolius (Dennst.) Nicolson. Biodiversitas 12: $7-11$.

Lamprecht I, Schmolz, Blanco L, Romero CM. 2002. Flower ovens: Thermal investigations on heat-producing plants. Thermochimica Acta 391: 107-118

Lamprecht I, Seymour RS. 2010. Thermology investigation of three species of Amorphophallus. J Thermal Anal Calor 102 (1): 127-136.

Mayo SJ, Bogner J, Boyce PC, 1997. The genera of Araceae. The Trustees, Royal Botanic Gardens, Kew.

Mutaqin AZ, Kurniadie D, Iskandar J, Nurzaman M, Partasasmita R. 2020. Ethnobotany of suweg, Amorphophallus paeoniifolius: Utilization and cultivation in West Java, Indonesia. Biodiversitas 21 (4): 1635-1644.

Prakash PS, Nayar NM. 2000. Thermogenesis in elephant foot yam, Amorphophallus paeoniifolius (Dennst.) Nicolson (Araceae). J Root Crops 26 (1): 10-14.

PunekarSA, Kumaran KPN. 2010. Pollen morphology and pollination ecology of Amorphophallus species from North-Western Ghats and Konkan Region of India. Flora 205: 326-336.

Putri I, Hintono A, Susanti S. 2018. Optimization of elephant foot yam (Amorphophallus paeoniifolius) extracts syrup formula as a nutritive antioxidant drink. Intl J Sustain Agric Res 5 (1): 1-9.

Raman V, Tabanca N, Demirci B, Khani IA. 2017. Studies on the floral anatomy and scent chemistry of titan arum (Amorphophallus titanum, Araceae). Turk J Bot 41: 63-74
Santosa E, Lian CL, Sugiyama N, Misra RS, Boonkorkaew P, Thanomchit K. 2017. Population structure of elephant foot yams (Amorphophallus paeoniifolius (Dennst.) Nicolson) in Asia. PLoS ONE 12(6): e0180000. DOI: 10.1371/journal.pone.0180000.

Santosa E, Sugiyama N, Nakata M, Lee ON, Trikoesoemaningtyas, Sopandie D. 2006. Flower Induction in elephant foot yams using Gibberellic Acid (GA3). Japan J Trop Agric 50 (2): 82-86.

Schaefer H, Rolshausen G. 2005. Plants on red alert: do insects pay attention? BioEssays 28: 65-71.

Seymour RS, Matthews PGD. 2006. The role of thermogenesis in the pollination biology of the amazon water lily Victoria amazonica. Ann Bot 98: 1129-1135.

Shirasu M, Fujioka K, Kakishima S, Nagai S, Tomizawa Y, Tsukaya H, Jin M, Manome Y, Touhara K. 2010. Chemical identity of a rotting animal-like odor emitted from the inflorescence of the titan arum (Amorphophallus titanum). Biosci Biotechnol Biochem 74: 25502554.

Singh A, Chaurasiya A, Mitra S. 2016. Assessment of nutritional composition in elephant foot yam (Amorphophallus paeoniifolius (Dennst) Nicolson) cultivars. Intl J Food Stud 5: 146-157.

Singh A. Wadhwa N. 2014. A review on multiple potentials of aroid: Amorphophallus paeoniifolius. Intl J Pharmaceut Sci Rev Res 24 (1): 55-60.

Soemono S, Baharsjah IS, Wiroatmodjo J, Tjitrosoedirdjo S. 1986. Effect of weight of seed corm on growth, yield and tuber quality of elephant yam (Amorphophallus campanulatus Bl.) at different ages. Bulletin Agricultura 17 (2) : 17-24. [Indonesian]

Sugiyama N, Santosa E, Nakata M. 2010. Distribution of elephant foot yams (Amorphophallus paeoniifolius) in Indonesia. Trop Agric Dev 54: 33-34.

Sugiyama N, Santosa E. 2008. Edible Amorphophallus in Indonesia: Potential crops in agroforestry. Gadjah Mada University Press, Yogyakarta.

Truyen DM, Mansor M, Ruddin AS. 2015. A note on aroids ethnobotany in Hau River, Vietnam. Trop Plant Res 2 (1): 58-63.

van der Ham RWJM, Hetterscheid WLA, van Heuven BJ. 1998. Notes on the genus Amorphophallus (Araceae)-8 pollen morphology of Amorphophallus and Pseudodracontium. Rev Palaeobot Palynol 103: 95-142

Yuzammi, Kurniawan A, Asih NPS, Erlinawati I, Hetterscheid W. 2017. The Amorphophallus of Indonesia. Center for Plant Conservation Botanic Gardens, Indonesian Institute of Sciences, Bogor.

Yuzammi, Witono JK, Hetterscheid WLA. 2014. Conservation status of Amorphophallus discophorus Backer \&Alderw. in Java, Indonesia. Reinwardtia 14 (1): 27-33.

Yuzammi. 2009. Phytochemical analysis and its correlation to morphological and genetic diversity of several types of tubers from the Araceae in Java. Final report on incentive program activities for researchers. Center for Plant Conservation Botanic Gardens, Indonesian Institute of Sciences, Bogor. [Indonesian] 